\title{
CORRIGENDUM
}

\section{The effects of concentrated barley $\beta$-glucan on blood lipids in a population of hypercholesterolaemic men and women}

By Joseph M. Keenan, Melanie Goulson, Tatyana Shamliyan, Nathan Knutson, Lore Kolberg and Leslie Curry

Volume 97 (2007) Number 6

pp 1165

The results of the report on "The effects of concentrated barley beta-glucan on blood lipids" in the June, 2007 issue of BJN were incorrectly reported. The last sentence of the second paragraph, p 1165, should read, "The $5 \mathrm{~g}$ HMW group experienced a $17 \%$ drop in LDL-C where LDL-C was reduced by $15 \%$ in the $5 \mathrm{~g}$ LMW group, $10 \%$ in the $3 \mathrm{~g}$ HMW group and $10 \%$ in the 3 g LMW group." 